\title{
ИНТЕРНАЦИОНАЛИЗАЦИЯ ЮАНЯ И ЕГО ЗНАЧЕНИЕ ДЛЯ РАЗВИТИЯ ВНЕШНЕТОРГОВОЙ ДЕЯТЕЛЬНОСТИ РОССИИ И КИТАЯ
}

\section{THE INTERNATIONALIZATION OF THE YUAN AND ITS IMPORTANCE FOR THE DEVELOPMENT OF FOREIGN TRADE ACTIVITIES IN RUSSIA AND CHINA}

Qin Zhizhen

Summary. One of the defining factors of the modern international monetary system is its vulnerability based on a single currency, which destabilizes the international financial environment and maintains an international payment imbalance. Among currencies that can play an important international role, the Chinese yuan (RMB) is gaining in importance. It is especially important that the Chinese authorities are actively involved in the internationalization of their currency and are consistently taking steps in this direction. The driving force behind these actions is the benefits that the country can obtain from the international use of the Chinese currency. The purpose of the article is to try to determine the relationship between the internationalization of the Chinese currency (in the global and regional markets) and the development of foreign trade activities of Russia and China. The implementation of the goal was based on a discussion of the determinants of the process of internationalization of the Chinese currency in the context of turbulence in world financial markets and the construction of a multipolar financial system.

Keywords: convertible currency, financial system, basket of currencies, export, international trade.
Д инамичный экономический рост Китая, который непрерывно продолжался с начала реформ в 1978 году, и его растущие позиции в мировой әкономике стали источником интенсивной дискуссии о роли юаня в международной валютной системе, которая продолжается в настоящее время вот уже несколько лет. Превращение юаня в международную валюту - лишь вопрос времени. Это должно привести к трансформации международной валютной системы, в которой в настоящее время доминирует доллар США, В сторону многополярной системы, основанной на нескольких резервных валютах. Доллар, евро и юань будут играть в этом центральную роль. В результате предполагаемого снижения важности доллара три наиболее важные резервные валюты будут играть почти равную роль,

\author{
Цинь Чжичжэнь \\ Аспирант, Государственный университет \\ управления \\ 308743965@q9.com
}

Аннотация. Одним из определяющих факторов современной международной валютной системы является ее уязвимость, основанная на единой валюте, что дестабилизирует международную финансовую среду и поддерживает международный платежный дисбаланс. (реди валют, которые могут играть важную международную роль, китайский юань (RMB) приобретает все большее значение. Особенно важно то, что китайские власти активно занимаются интернационализацией своей валюты и последовательно предпринимают шаги в этом направлении. Движущей силой этих действий являются выгоды, которые страна может получить от международного использования китайской валюты. Цель статьи - попытаться определить взаимосвязь между интернационализацией китайской валюты (на глобальном и региональном рынках) и развитием внешнеторговой деятельности России и Китая. Реализация цели была основана на обсуждении детерминант процесса интернационализации китайской валюты в контексте турбулентности на мировых финансовых рынках и построения многополярной финансовой системы.

Ключевые слова: конвертируемая валюта, финансовая система, корзина валют, экспорт, международная торговля.

что повысит стабильность международной валютной системы [6].

Можно согласиться с тем, что международная валютная система уже превратилась в трехполюсную систему, основанную на долларе, евро и юанях [8]. Есть также мнения, что подъем Китая до позиции крупнейшей экономики мира и снижение экономического значения Соединенных Штатов приведет к снижению роли доллара и юань станет доминирующей международной валютой. В настоящее время китайский юань еще не является полностью конвертируемой валютой, но его роль в международной торговле и финансах неуклонно растет. Интернационализации юаня способствует большая доля Китая в мировой экономике, а высокие валютные резервы яв- 
Таблица 1. Функции международной валюты $[1,11]$

\begin{tabular}{|c|c|c|}
\hline Функция денег & Частная сфера & Официальная сфера \\
\hline Мера ценности & $\begin{array}{l}\text { Валюта для выставления счетов } \\
\text { по коммерческим сделкам и котировки } \\
\text { мировых цен }\end{array}$ & $\begin{array}{l}\text { Базовая валюта в принятой в стране } \\
\text { системе обменного курса }\end{array}$ \\
\hline Платежные средства & $\begin{array}{l}\text { Валюта операций (платежей) } \\
\text { в международной торговле и обмене } \\
\text { валюты }\end{array}$ & $\begin{array}{l}\text { Валюта интервенции, в которой } \\
\text { центральный банк проводит интервенции } \\
\text { на валютном рынке }\end{array}$ \\
\hline Мера накопления & $\begin{array}{l}\text { Инвестиционная валюта, в которой } \\
\text { номинированы активы частных } \\
\text { инвесторов }\end{array}$ & Резервная валюта центрального банка \\
\hline
\end{tabular}

ляются основой его стабильной стоимости. Основными моментами в этом процессе было заключение Народным банком Китая соглашений об обмене с несколькими центральными банками, создание оффшорных рынков в мировых финансовых центрах для транзакций в юанях (RMB-Offshore-Clearing - Hubs) и включение юаня в корзина валют, лежащая в основе определения стоимости СДР ${ }^{1}$. В связи с указанным выше становится актуальной раскрытие темы настоящей статьи, изучение ключевых аспектов интернационализации национальной валюты Китая в контексте ее значения для развития внешнеторговой деятельности с Россией.

В результате быстрого экономического развития за последние несколько десятков лет Китай превратился из бедной и закрытой аграрной страны в глобальную экономическую державу. С 2009 года он является крупнейшим в мире экспортером товаров, с 2010 года занимает второе место по объему ВВП, а с 2014 года обладает самым высоким в мире ВВП по паритету покупательной способности и крупнейшими валютными резервами. Интернационализация китайской валюты не последовала за ростом роли Китая в мировой экономике в течение почти 30 лет с начала системной трансформации. Ситуация стала меняться только с началом мирового финансово-экономического кризиса. Сегодня, хотя юань еще не является полностью конвертируемой валютой, он играет значительную роль на валютных рынках [5].

Международная валюта - это деньги, которые используются не только в стране эмитента, но и за рубежом, выполняя там основные денежно-кредитные функции, как в частной сфере (частные лица, экспортеры, импортеры, банки и другие финансовые организации, совершающие операции в иностранной валюте) и в официальной сфере (правительства, центральные банки). В то же время она должна играть значительную роль в международной торговле и финансовых операциях. Функции международной валюты можно представить в таблице ниже.

Специальные права заимствования
Основными предпосылками функционирования денег определенной страны или группы стран в качестве международной валюты являются [10]:

- полная конвертируемость валюты, доступная для всех экономических субъектов (резидентов и нерезидентов), и для всех типов операций (текущие и капитал);

- значительная доля страны или валютной зоны, выпускающей валюту, в международной торговле и международных потоках капитала, что связано с большим количеством и стоимостью сделок, заключенных этой страной;

- стабильное правовое регулирование и взвешенная экономическая политика правительства, которая является основой гармоничного функционирования государства и финансовой системы страны, гарантируя доверие к выпущенным деньгам;

- стабильный уровень цен и стабильный обменный курс, что дает инвесторам уверенность в сохранении покупательной способности валюты в будущем;

- хорошо развитый, эффективный, глубокий и ликвидный финансовый рынок, основанный на сильной институциональной и технической инфраструктуре, позволяющий эффективно выполнять и урегулировать международные транзакции.

После краха Бреттон-Вудской системы в начале 1970-х годов в мире была разработана многообменная система, в которой функцию международной валюты выполняли несколько ключевых валют, при этом доллар США являлся передовой валютой. Выбор валюты для отдельных функций в международной торговле, помимо вышеупомянутых предпосылок, также зависит от таких факторов, как:

- исторически сложившиеся обычаи во внешней торговле и международных финансах;

- переговорная сила деловых партнеров, которые, выбирая валюту выставления счетов и платежа, стремятся снизить риск обменного курса;

- появление в торговле между промышленно развитыми и слаборазвитыми странами тенденции вы- 


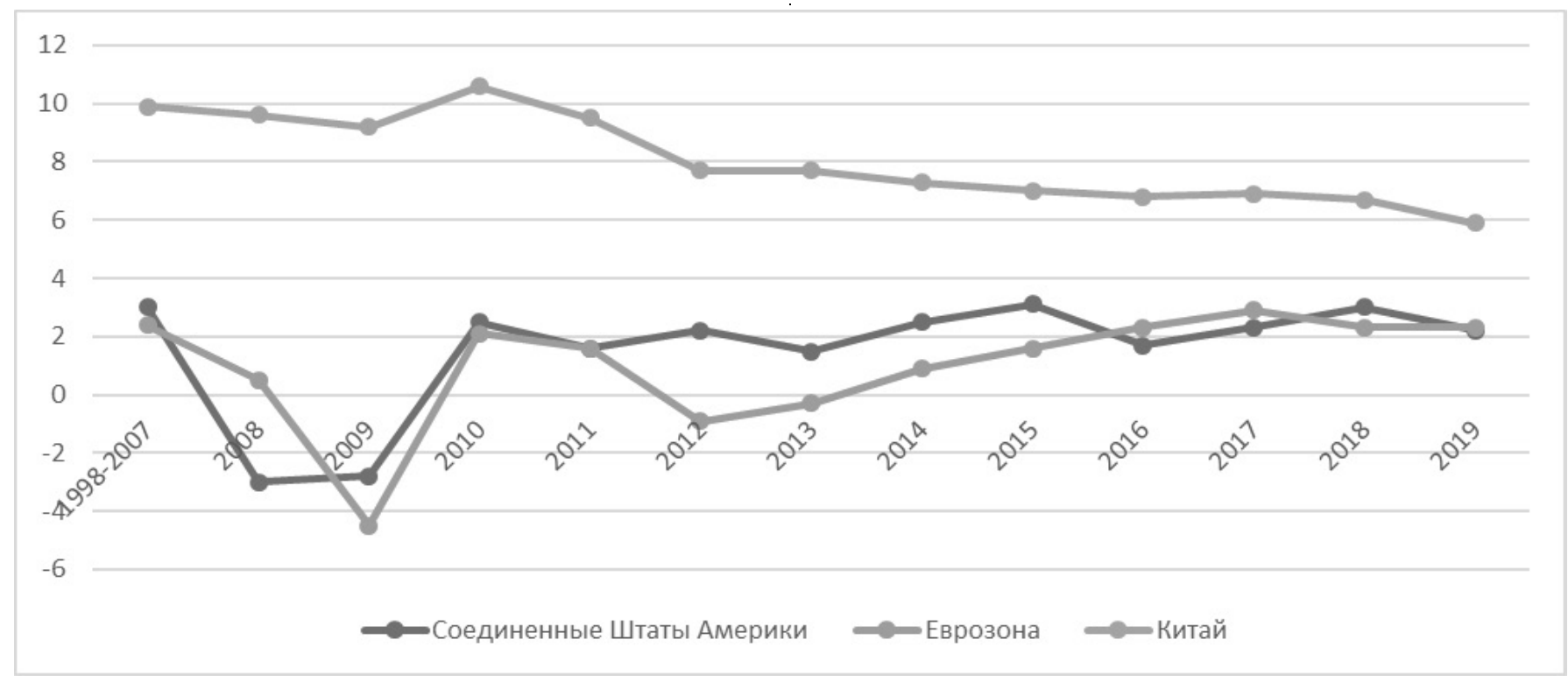

Рис. 1. Темпы роста США, Китая, стран Еврозоны,\% [7]

ставлять счета и расчеты по операциям в валютах развитых стран, в т.ч. потому что цены на основных товарных биржах мира указаны в долларах, фунтах, иенах или евро.

Размер и высокая доля китайской экономики в мировой экономике являются наиболее важными причинами интернационализации китайской валюты. С 1980-х годов по настоящее время темпы роста ВВП Китая были в несколько раз выше, чем у его основных конкурентов в мире: США и зоны евро (рис. 1).

В результате доля Китая в мировом ВВП увеличилась, как и в мировом экспорте. В 2014 году Китай вышел на первое место в мире по ВВП, измеренному по паритету покупательной способности. Китай с численностью населения вдвое больше, чем в США и зоне евро вместе взятых, является самой густонаселенной страной в мире. Таким образом, у них больше всего потенциальных потребителей и сотрудников, многие из которых являются высококвалифицированными и трудолюбивыми. С 2009 года Китай был крупнейшим экспортером с 10,5\% мирового экспорта. Его экспорт, как и импорт, ранее в значительной степени был сосредоточен в странах Азии. Сегодня в период пандемии коронавируса можно сказать, что экспорт Китая продвинулся дальше и увеличивается практически во всех регионах мира. В течение многих лет в Китае наблюдается положительный торговый баланс и большой профицит текущего счета [2].

Рассматривая причины интернационализации юаня, нельзя игнорировать международную инвестиционную позицию Китая. Международная инвестиционная пози- ция страны - это совокупность ее иностранной дебиторской задолженности (активов) и обязательств (обязательств) на данный момент времени. Она указывает, является ли страна чистым кредитором или должником перед остальным миром [9].

Экономический кризис, произошедший в мире после 2007 года, не уменьшил доверия инвесторов к китайскому рынку. Более того, эти вложения не принесли убытков, которые следовало бы списать с их стоимости. Первоначально иностранные компании строили в основном заводы в Китае, которые производили товары, продаваемые в основном на более развитых рынках. Таким образом, большая часть доходов от таких операций была получена в валютах, отличных от юаня. В настоящее время иностранные компании видят возможность продавать товары и услуги на китайском рынке, а это означает, что большая часть доходов от таких инвестиций будет получена в юанях. Это явление также может способствовать интернационализации региона Балтийского моря. Стоимость китайских иностранных инвестиций росла несколько менее динамично, они фокусируются на рынке месторождений природных ресурсов, которые необходимо импортировать в Китай (в частности, это энергоресурсы). Рост китайских ПИИ способствует развитию международной торговли между предприятиями, принадлежащими китайским владельцам. Поэтому можно ожидать, что многие из этих транзакций будут совершаться в юанях, что также способствует интернационализации валюты.

На инвестиционную позицию Китая, как и любой другой страны, влияют три основных фактора: уровень офи- 
циальных валютных резервов Китая. Резервные активы, накопленные в Народном банке Китая, имеют большое значение для стабильности юаня, что имеет решающее значение для интернационализации валюты. В случае сильного обесценивания или спекулятивных атак на валюту их можно использовать для поддержания ее стоимости. Сегодня запасы КНР остаются крупнейшими в мире.

Причины накопления столь крупных валютных резервов можно увидеть в международной торговой политике властей КНР. В течение многих лет Китай получал большое положительное сальдо торгового баланса, что оказывало сильное давление на рост обменного курса его валюты по отношению к доллару, что, как следствие, могло ослабить конкурентоспособность китайского экспорта и вызвать рост безработицы в Китае, стране, грозящей вспышкой социальных волнений. Экспортный сектор Китая поглощает миллионы рабочих, которые не работают в сельском хозяйстве и массово переезжают в города. В то же время экспорт является одним из важных драйверов динамичного экономического развития Китая.

Для России взаимное сотрудничество является стратегическим приоритетом государственной политики [3]. Сотрудничество между Российской Федерацией и Китайской Народной Республикой сегодня является самым интенсивным с момента подписания Договора о дружбе в 2001 году. Китайские компании в России участвуют в реализации около 30 инвестиционных проектов на общую сумму около 22 миллиардов долларов, а объем торговли ежегодно увеличивается. Особенно интенсивно данные процессы стали протекать после 2014 г. и введения санкций в отношении России со стороны США и стран Еврозоны, а также ответных российских контр-санкций. В результате между странами происходит углубление сотрудничества в секторах энергетики, авиации и связи, а также в новых областях, таких как сельское хозяйство, финансы, технологии и электронная промышленность. Всего подписано около 30 контрактов. Пожалуй, наиболее обсуждаемым стал контракт между российской телекоммуникационной компанией МТС и китайской компанией Huawei о развитии сети $5 G$ в России.

Россия понимает, что это связано в том числе с тем, что США объявили санкции против телекоммуникационного гиганта. Примечательно также подписание соглашения китайским гигантом интернет-продаж Alibaba c pocсийской стороной о создании совместного предприятия электронной коммерции под названием AliExpress Pocсия. С российской стороны акционерами являются телеком «Мегофон», интернет-группа Mail.ru и государственный инвестиционный фонд РФПИ. Еще одно соглашение, заслуживающее внимания,- - это соглашение между российской частной компанией «Новатэк» и Газпромбанком с китайской Sinopec о продаже газа Китаю. Также подписано соглашение о создание фонда исследований и технологических инноваций на сумму около 1 миллиарда долларов США. Его профинансируют российский инвестиционный фонд РФПИ и Китайская инвестиционная корпорация.

Данные направления сотрудничества предопределяют развитие внешнеторговой деятельности, которая может активизироваться с учетом использования сделок в китайских юанях. Конечно, России нужно понимать, какие риски есть во взаимодействии с Китаем. В экономическом отношении связи между двумя странами нельзя назвать равноправными. Экономика Китая в восемь раз больше экономики России и растет быстрее, темпы роста в Китае в четыре раза выше, чем в России, поэтому эта разница в экономическом потенциале будет увеличиваться. Россия не должна стать лишь источником поставок природных ресурсов и необработанных товаров на китайский рынок. Поэтому все экономические взаимосвязи России нужно направлять в перспективные отрасли с высокой добавленной стоимостью [4].

Процесс интернационализации юаня ускорился за счет создания оффшорных рынков сначала в Гонконге, а затем в других глобальных финансовых центрах для операций с китайской валютой, которые назывались RMBOffshore-Clearing-Hubs. K концу 2015 года было создано несколько таких хабов, в т.ч. во Франкфурте-на-Майне, Лондоне, Париже, Люксембурге и Цюрихе, при этом оффшорный центр Гонконга является наиболее важным. Каждый оффшорный центр имеет клиринговый банк, который ведет счета в юанях для других банков и предприятий. Они позволяют осуществлять платежи в китайской валюте с организациями в Китае, Гонконге и других оффшорных центрах, тем самым увеличивая использование китайской валюты в международных транзакциях.

В ноябре 2015 года Международный валютный фонд решил, что с 1 октября 2016 года юань будет включен в качестве пятой валюты (после доллара, евро, иены и фунта стерлингов) в корзину валют, которые являются основой для определения стоимости специальных прав заимствования (СДР). Это означает признание китайской валюты в качестве официальной резервной валюты в мире, что имеет большое политическое и престижное значение для Китая. Первоначально практическое значение этого акта не будет большим, но в долгосрочной перспективе он внесет значительный вклад в то, что юань перестанет быть евро, а станет второй по значимости международной валютой. В конце 2015 года Китай запустил систему, позволяющую легко проводить трансграничные транзакции, деноминированные в юанях (China International Payment System - CIPS), к которой было подключено множество банков, в том числе иностран- 
ных (HSBC, Citibank, Deutsche Bank и другие). Это альтернатива расчетам с банками-корреспондентами в Китае или в одной из клиринговых организаций, расположенных в оффшорных финансовых центрах. CIPS совместим с системой SWIFT. Устранение посредников позволяет снизить транзакционные издержки во внешней торговле с Китаем.

Таким образом, Китайская Народная Республика стремится сделать юань международной валютой наравне с евро и долларом. Китайский юань в настоящее время является важной альтернативой доллару США и евро с точки зрения их функционирования в качестве международных валют. Китайские власти проводят много мероприятий, направленных на интернационализацию юаня, чтобы он стал основной валютой не только в региональном масштабе, но и в объеме мирового валютного оборота. В то же время для достижения этой цели требуется создание правовой и финансовой системы, соответствующей мировым стандартам, с привлечением многих финансовых учреждений со всего мира и наличием профессиональных сотрудников.

Однако будущее юаня как международной валюты под вопросом по ряду причин. Вероятно, для того, чтобы юань смог получить такой статус, он должен стать полностью ликвидной валютой, в значительной степени независимой от государственного вмешательства. Учитывая значительное положительное сальдо торгового баланса, создаваемое китайским экспортом, это, вероятно, будет означать быстрое повышение курса валюты. Это, в свою очередь, нанесло бы ущерб международной конкурентоспособности китайской продукции. Более того, действия китайских денежных властей были направлены на предотвращение чрезмерного повышения курса юаня.

Несмотря на возросшую гибкость в этом отношении в последние годы, нет никаких признаков того, что эта стратегия радикально изменится в течение следующих нескольких лет. С другой стороны, китайская экономика становится все менее зависимой от экспорта из-за динамично развивающегося внутреннего спроса. В связи с чем важным становится активизация двустороннего экономического взаимодействия Китая и других государств, в том числе России. Интернационализация юаня может принести значительные выгоды Китаю в случае проведения сделок с Россией в юанях, с другой стороны России необходимо проводить осторожную политику в данном направлении, выбирая направлении сотрудничества с точки зрения возможности повышения инновационности развития российской экономики и увеличения высокотехнологичных товаров во внешнеторговой деятельности с Китаем. Вероятно, в ближайшие десять или около того лет юань присоединится к группе трех наиболее важных международных валют - после доллара и евро. Путь к достижению этого - введение полной конвертируемости юаня и дальнейшая либерализация оборота капитала с зарубежными странами.

\section{ЛИТЕРАТУРА}

1. Андрианов В.Д. Современные тренды В трансформации глобальной банковской и финансовой инфраструктуры // Россия: тенденции и перспективы развития. 2021. № 16-1. С. 17-31.

2. Гордон А.В. Возвышение Китая в парадигме глобализации // РСМ. 2020. № 2 (107). С. 95-112.

3. Кондратов Д.И. БРИКС в условиях глобальной нестабильности: новые вызовы и перспективы развития // Российский внешнеэкономический вестник. 2021. № 1. С. 74-92.

4. Кыялбековна Э.А. Перспективы развития товарооборота между Россией и Китаем // Скиф. 2020. № 4 (44). С. $732-736$.

5. Лексютина Я.В. Усилия БРИКС по изменению мировой валютно-финансовой системы // Дайджест-финансы. 2019. № 4 (252). С. $448-465$.

6. Морозов Ю.В. Глобальные позиции Китая и перспективы их развития в XXI веке // Китай в мировой и региональной политике. История и современность. 2020. № 25. C. 80-95.

7. Сайт Всемирного банка. URL: https://datatopics.worldbank.org/world-development-indicators/

8. Хейфец Б.А., Чернова В.Ю. Роль Китая в глобализации мировой экономики // Россия и современный мир. 2021. № 2 (111). С. 100-120.

9. Ши Икэ, Эпова Н.Ф. Влияние внешнеторговой политики на экономическое развитие Китая // Российско-китайские исследования. 2021. № 1. С. 25-35.

10. Chernilevskaya K.E. Internationalization of renminbi as a function of china's foreign exchange policy // Вестник РУДН. Серия: Политология. 2021. № 2. С. 233242.

11. Zharikov M. The instruments to reform the world system of currencies: internationalising the currencies of the BRicS // Review of Business and Economics Studies. 2018. № 3. C. 19-28. 